REVIEW

\title{
Clinicians taking pictures - a survey of current practice in emergency departments and proposed recommendations of best practice
}

\author{
P Bhangoo, I K Maconochie, N Batrick, E Henry
}

Emerg Med J 2005;22:761-765. doi: 10.1136/emj.2004.016972

The primary objective of this survey was to establish current practice in emergency departments in the UK. Variation in obtaining consent, how image collection is achieved, and the images stored were considered to be important outcomes. An initial postal questionnaire followed by phone survey posed questions about practical and procedural issues when capturing clinical images in emergency departments in the UK. Altogether, 117 departments replied out of 150 surveyed. Only 21 departments have a written policy permitting medico-legal case photography. A total of 53 do take clinical photographs where no policy exists, seven of which actively take assault/domestic violence images, only four of which document consent. All departments with photographic facilities take images for clinical/teaching purposes. Thirty two of those without a policy attach the photograph to the clinical notes and so may be potentially called upon for medico-legal proceedings if relevant, which raises issues of adequate consent procedures, storage, and confidentiality. This is particularly pertinent with the increasing use of digital photography and image manipulation. A large variation in current practice has been identified in relation to a number of issues surrounding clinical image handling in emergency departments. Subsequently, recommendations for best practice have been proposed to protect both the patient and the clinician with regards to all forms of photography in the emergency department setting.

See end of article for authors' affiliations

Correspondence to: P Bhangoo, Emergency Department, Central Middlesex Hospital, Acton Lane, Park Royal NW10

7NS, UK; pbhangoo@ doctors.org.uk

Accepted for publication 4 August 2004 is an increasing use of these images for medical education and research.

There are risks, however, for the patient and the clinician by taking these images if certain safeguards are not followed-for example, breach of confidentiality, invalid consent procedures, the use of material outside of their intended purpose, and access of the images by unauthorised personnel. The use of clinical images is a potential minefield for litigation unless best practice is followed.

The primary objective of our postal questionnaire was to establish what is current practice in emergency departments in the UK on clinical photography—-film and digital—and to ascertain how many departments had written guidance about all aspects of this.

Following collation and interpretation of the information yielded by the survey and using other reference sources-for example, General Medical Council consent guidelines-we have proposed specific recommendations of best practice to protect both the patient and clinician in the emergency setting.

\section{METHOD}

Altogether, 150 questionnaires with self addressed return envelopes were sent to accident and emergency (A\&E) departments throughout the UK. It posed the question "Does your department have a written policy for the use of clinical photography (including medico-legal cases)" and asked which form of photographic media is used in the department (table 1 for the questionnaire in full). A repeat posting of the same questionnaire was followed by telephoning the departments that had either provided incomplete replies or which had failed to respond to the two postings.

\section{RESULTS}

Initially 70 questionnaires were returned, after which a second batch were resent to the departments that failed to reply. This led to a further 27 completed questionnaires being returned. A phone survey was then conducted and a final response rate of $78 \%(117 / 150)$ was achieved. Replies were from consultants, specialist registrars, and senior nursing staff.

The data were analysed under two categories: those with and those without a written policy.

Abbreviations: A\&E, accident and emergency; NAl, non-accidental injury 
Table 1 The questionnaire sent to UK accident and emergency departments

Does your department have a written policy for the use of clinical photography?

Does your department take photographic images in the following cases and if so please give details of format, consent, documentation, and

image storage

1. Domestic violence

1. Assault

1. Non-accidental injury

1. Teaching

1. Clinical purposes

The results are tabulated in table 2 and fig 1 and discussed in further detail below.

\section{Departments with written policy on taking images}

Altogether, 41 emergency departments (36\%) have an existing policy about the use of photography; 20 do not take photographs in cases of assault and domestic violence. Of these departments, four use the images for teaching purposes only so patients cannot be identified from the image thereby avoiding any medico-legal difficulties.

The remaining 21 have a documented policy for taking medico-legal and clinical/teaching photographs. Four of the 21 have an annual staff training programme (mainly involving senior nursing staff), detailing the indications for imaging, the need for consent, photographic techniques, and storage of the subsequent images.

Those using Polaroid (14) all applied patient labels to the reverse of the image ( 10 included name and address, 4 only patient hospital number). Only four departments required images to be signed by the photographer. Those Polaroid images not kept with the notes could only be accessed through the Trust's medico-legal department.

Of those using digital cameras (9), two printed the image immediately after capture and labelled the reverse with the patient's label and then deleted the image (only two of which were cross-signed). The remaining departments stored the images on disk, which could only be accessed by named senior staff. However, only two of the seven departments were aware that they were using specific software packages that did not allow image manipulation.

Only two departments have a written policy addressing photography for clinical and educational purposes. A consent form is printed on the A\&E card then the images are taken, either digital or Polaroid, and then scanned by the medical illustration department who store and categorise them separately from the patient's notes.

Departments without written policy on taking images Of the $74(63 \%)$ departments that have no written policy, 21 actually have no facilities to take photographs. However, six departments commented that their medical illustration department could take photographs during working hours.

If a Polaroid picture is taken then in all cases the image is attached to the medical notes in anticipation of the patient's next attendance-for example, at review clinic. Digital images (21 departments) are stored on a departmental computer in 5/21, with the images being deleted after the patient has been discharged. The remaining 16 departments only store the image until the referral has been made to specialist team, at which point the image is shown and then deleted.

Written consent for photographs used for clinical assessment is documented in the medical notes in only 10 out of 53 departments.

Seven $(13 \%)$ of those with cameras do take photographs in cases of assault and domestic violence even though there is no formal/written policy. Of these, only 4/7 document consent. All used patient hospital labels for identification.

One department reported that they have since discarded their camera after the staff member who took the image for clinical purposes was called to court to testify to its authenticity.

None of the departments surveyed, with or without policies, took photographs in suspected NAI cases. All have local departmental guidelines for referral to specialist hospital or community paediatricians.

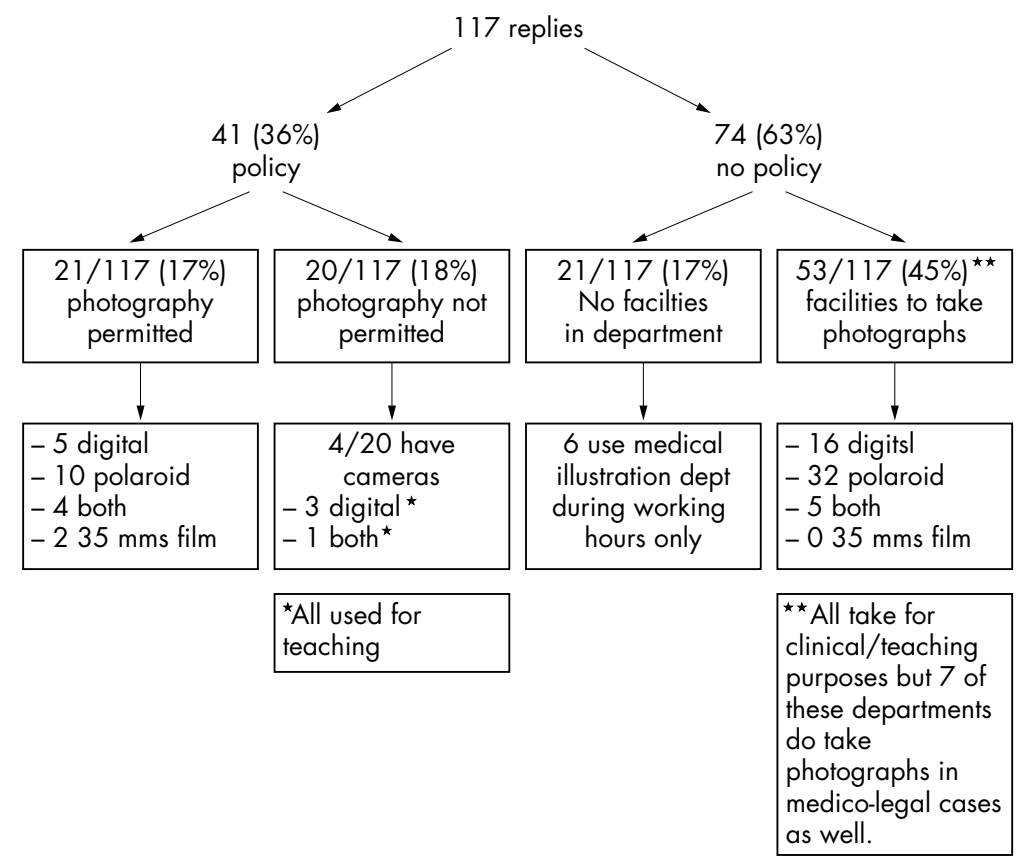

Figure 1 Results of the questionnaire 


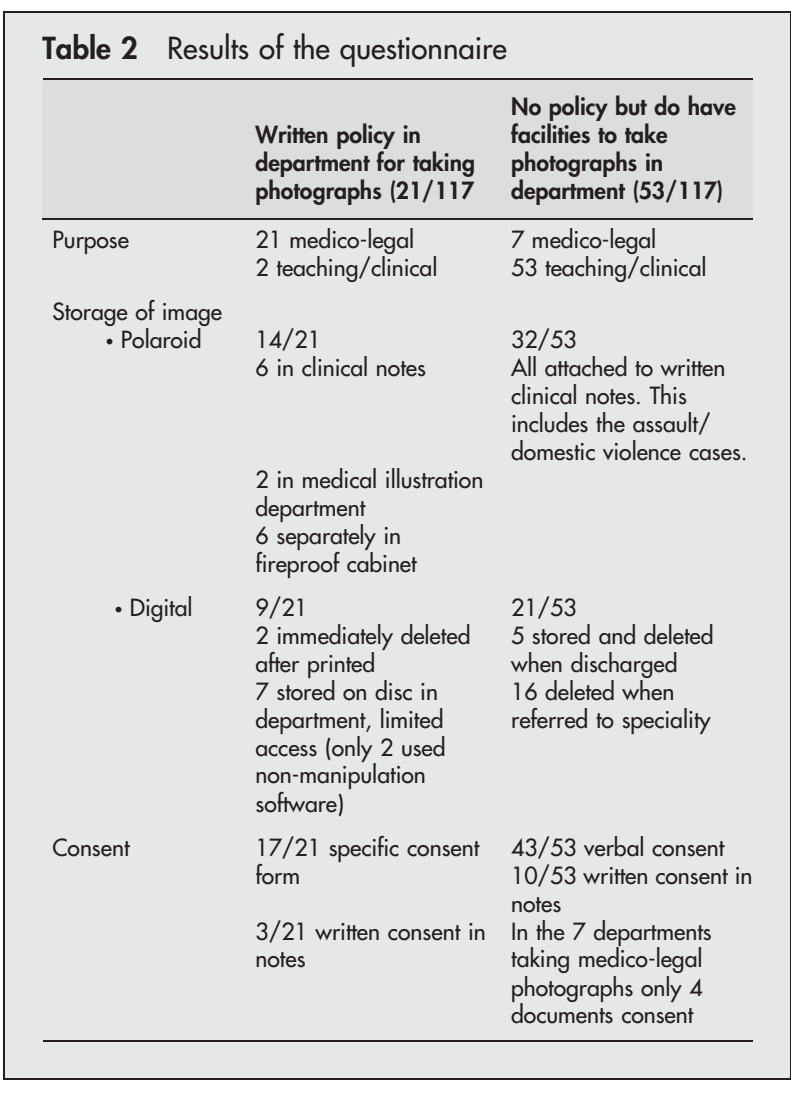

\section{DISCUSSION}

Should clinicians be taking images in emergency departments at all considering the potential legal implications? Certainly the survey has highlighted how much variation there is in practice-for example, from how and if consent is obtained, to patient identification, and the potentials for breaches of confidentiality. General Medical Council guidelines published in 2002 on Making and Using Visual and Audio Recordings of Patients ${ }^{1}$ advises on the use of images for clinical, educational, and research purposes.

\section{Consent}

Images taken for clinical purposes form part of the patient's health record. Consent to $x$ rays and ultrasound investigations are given implicitly by the patient undergoing those procedures. Similarly, by presenting for treatment and investigation, the patient enters into a tacit agreement to documentation, which includes images as well as written information.

An image taken for the purpose of treating a patient must not be used for any other purpose without express consent. However, if such an image is subsequently to be published, or used for educational research, written consent must be sought for that specific purpose. Consent is not required when the image taken for treatment or assessment does not allow for the patient to be recognised; in this case, the image can be used for educational or research purposes, with the caveat that "express consent must be sought for any form of publication". When making a judgement about whether the patient may be identifiable, one should bear in mind that apparently insignificant features may still be capable of identifying the patient to others. As it is difficult to be absolutely certain that a patient will not be identifiable, clinical photographs should not be published or used in any form to which the public may have access without the consent of the patient. ${ }^{1}$

If the patient is unable to give consent when the image is taken-for example, he or she is unconscious-then the image cannot be used until the patient has the capacity to give consent. Permission may be given by the immediate family if the patient is likely to be permanently incapacitated. Young people aged 16 years or over are assumed to be competent to give consent; under this age, Gillick competency $^{2}$ (the level of competence of an individual in decision making referred to in Gillick v. Norfolk \& Wisbech Area Health Authority) to give consent may have to be determined.

It must be explained when obtaining consent that once the image is in the public domain, it is difficult to control its future use and it may not be possible to withdraw the image. Latest General Medical Council guidelines, published in April 2004, detail all aspects of patient confidentiality and consent procedures. ${ }^{3}$

2. Confidentiality, document storage, and authenticity Confidentiality is essential in any clinical consultation. The Data Protection Act $1998^{4}$ covers all NHS material concerning any individual patient (with the exception of anonymised information), including electronic or paper documentation. "Disclosures required by law or made in connection with legal proceedings" are exempted from the non-disclosure provisions by virtue of section 35 of the Act.

The Act aims to protect the controlled flow of data while ensuring that confidentiality is not undermined. More recently, the Caldicott Report $2000^{5}$ addressed concerns about the ease with which data can be disseminated. Patient confidentiality must be maintained and the patient's best interest ensured when sharing information between NHS and non-NHS bodies.

How the images are stored and shared are key elements in maintaining patient confidentiality. Storage of the image varies according to the media used. Concerns about digital storage and possible digital image manipulation can be minimised by the use of software packages that prevents digital image manipulation (addressed later). Some departments also print off hard copies and subsequently delete the image in the digital camera. This printed image is stored in the written medical notes or is filed separately, and is accessible through the NHS Trust's medico-legal department. If the image is kept on disk it may not be acceptable for legal purposes as it is not stored by a secure system.

Polaroid images are stored with the notes or in a separate sealed envelope, and the image may have a patient label affixed to the back; some departments encourage the photographer to sign across and beyond the label to avoid the suggestion of tampering.

Departments using film photography have an agreement with their medical illustration department to develop the films in-house to avoid sending films outside for processing; medical illustration departments retain a copy of the image.

When printing the image it is recommended that photographic materials are processed within the hospital under secure arrangements. ${ }^{6}$

\section{Authenticity of digital photography}

Authenticity and admissibility of digital images as legal evidence has been addressed by The Fifth report and Eighth Report (House of Lords Select Committee on Science and Technology, 1998 $7^{78}$ as there is the potential for alteration of the image so jeopardising its value in legal proceedings. Key recommendations were the use of an audit trail and proposals for the use of image watermarks; the audit trail should follow how an image has been used once obtained. This trail includes using computer software and operating system technology so that any processing an image has undergone is thoroughly documented. The British Standards Institution Code of Practice for the Legal Admissibility of Information on Electronic Management Systems ${ }^{9}$ sets out approved procedures and documentation for the monitoring 
of systems producing evidential images. The British Standards Institution Code stresses that the way in which the image is managed is as important as the technology used. CD-ROM is cited as the most up to date storage mode as WORM (write once read many times) format; this is specified as the standard device for storing data in the Code.

Watermarks are being developed to "brand" a digital image. The watermark is hidden within the image and it requires specific software for it to be visualised. The invisible watermark may be permanent. Even more useful for evidential purposes is the development of a fragile watermark that is destroyed by any processing or modification of the original captured image.

\section{Image quality}

Accurate colour rendition and image definition are vital. Studies have shown no gain in diagnostic quality over analogue images. ${ }^{10}{ }^{11}$ This debate will continue as there are many variables: from any effect of magnification, to different camera resolutions, and the accuracy of the computer scanners/printers reproduction of the original image. Cost and issues of practicality have a bearing-for example, the ease of use of the chosen type of camera, how to store the image, and its processing, as well as maintaining the image's authenticity impact on this debate.

\section{RECOMMENDATIONS}

\section{Consent}

Consent procedures should be followed by those involved with obtaining clinical images, as this will protect the clinician and patient from misuse or misunderstanding about the intended use of the image.

Although consent is not required for an anonymised image to be used for educational purposes it is common courtesy to explain how the image will be used, particularly as it may come into the public domain.

Although an image that is solely to be used for treatment/ clinical purposes does not require written consent, the existence of a written statement for consent stating the use of the material would help protect the patient and clinician in the event of litigation.

Ideally written consent should include:

1. An explanation of the need for and purpose of such documentation.

2. That the images will form part of their confidential health records.

3. These images may be used for research or educational purposes, or both.

4. The name and signature of the medical practitioner and consultant.

If consent for clinical purposes only has been given then it must be clearly recorded as such.

\section{Identification and verification}

This is mainly of concern with evidential photography. The following should be recorded:

1. Date and time.

2. Name of consultant, photographer, and any others present, including chaperone and parents/guardians in NAI cases.

3. Camera used and film type.

4. Number of images captured.

5. Sites at which photographs taken documented on a drawn (or template) body map in notes.

Each image and print should be labelled. There is debate as to whether the patient's hospital number alone is adequate or whether more patient detail (including date of birth and name), as well as time, date, and name of photographer are required; however, it is suggested that more identifiers than just hospital number are used to eliminate difficulties with identification at a later date.

\section{Storage and disposal of unwanted images}

For treatment purposes only, storing prints within the patient's medical notes may be the most appropriate option.

In medico-legal cases, hard copies should be developed and stored in-house, in a fireproof cabinet, in a sealed envelope away from the notes, accessible only to senior named staff. Alternatively all hard copy images can be scanned or copied by the medical illustration department where they can be stored and categorised.

Destruction of unwanted hard copies should be by shredder/incineration, ideally in the department. ${ }^{9}$

Digital images should be captured and stored by computer software packages that cannot be manipulated or hard copies produced, and stored as above and the original captured image deleted.

\section{Written statement}

The photographer is rarely required to give evidence in court; this may be further minimised by including a comprehensive contemporaneous written statement when the image is taken. This ideally should include all the points mentioned under patient verification as well:

- That the photographs are a true likeness of the injuries at the time the images were taken.

- At whose request the photographs were taken (particularly important in NAI).

- Who has possession of the original images?

This information can thereafter be transposed onto a police statement form, which will contain the following formal declaration: "This statement, consisting of $\mathrm{x}$ pages each signed by me, is true to the best of my knowledge and belief and I make it knowing that, if it is tendered in evidence, I shall be liable to prosecution if I have wilfully stated anything which I know to be false or do not believe to be true."

As a general rule, this should obviate the need for oral testimony.

\section{Departmental policy}

If any form of patient photography is to be allowed then a clearly written easily accessible policy should exist to protect both the patient and staff. This should include guidance for clinical and teaching image capture covering the above mentioned recommendations.

If photography is to be allowed for medico-legal purposes there should be clear guidelines and proformas to aid adequate/appropriate documentation in these cases and consideration should be given to senior staff undergoing appropriate training. Guidelines in medico-legal cases should include:

1. Written consent forms (ink stamps for clinical purposes).

2. History and examination sheets, including body maps.

3. If images are not taken then set procedures-for example, police photography or medical illustration should be encouraged where possible.

4. Identification and verification if images are taken.

5. Written statement (as mentioned above) if photography is to be allowed on site.

6. Image storage.

7. Contact details of appropriate staff, including domestic liaison staff, social workers, local police, and refuge centres.

\section{CONCLUSION}

Whether for education, clinical, or medico-legal purposes, the taking, storing, and use of an image raises the issues of 
consent and confidentiality. We have highlighted a large variation in practice in emergency departments in the United Kingdom that are using photography routinely (whatever the indication may be), but recommend that a written policy in each department, covering all aspects of photography, is mandatory.

By implementing a nationally accepted standard of practice on consent, patient identification, image storage, and documentation, best practice can safeguard the interests of the patient and the clinician.

\section{Authors' affiliations}

P Bhangoo, I Maconochie, N Batrick, Accident and Emergency

Department, St Mary's Hospital, London, UK

E Henry, Barrister, Hollis Whiteman Chambers, Temple, London, UK

Competing interests: none declared

\section{REFERENCES}

1 Making and using visual and audio recordings of patients. 2002. http:// www.gmc-uk.org/standards/default.htm (accessed 29 May 2004).
2 Gillick v West Norfolk and Wisbech Area Health Authority. 1985. http:// www.hrcr.org/safrica/childrens_rights/Gillick_WestNorfolk.htm (accessed 30 June 2004).

3 Confidentiality: protecting and providing information. 2004. http:// www.gmc-uk.org/standards/default.htm (accessed 29 May 2004).

4 Department of Health. The Data Protection Act. 1998. http:// www.doh.gov.uk/dpa98 (accessed 20 October 2003).

5 The Caldicott Committee. Report on the review of patient-identifiable information. 1997. http://www.doh.gov.uk/confiden/crep.htm laccessed 21 October 2003)

6 Cull P, Gilson CC. Confidentiality of illustrative clinical records code of practice, guidance notes and recommendations. J Audiov Media Med 1986;9:124-30.

7 House of Lords Select Committee on Science and technology. Fifth Report. 1998. http://www. parliament.the-statinery-office.co.uk/pa/ld200102/ Idselect/lddelreg/50/5002.htm (accessed 14 October 2003).

8 House of Lords Select Committee on Science and technology. Eighth Report. 1998. http://www.parliament.the-statinery-office.co.uk/pa/ld200102/ Idselect/lddelreg/50/5002.htm (accessed 14 October 2003).

9 British Standards Institution. A code of practice for the legal admissibility of information on electronic document management systems. 1996: 206-7, http://www.bsi-global.com/portfolio+of+Products+and +services/ Books+Guides+Management/pd0008xalter (accessed 5 December 2003)

10 Smith J. Digital imaging: a viable alternative to conventional medico-legal photography? J Audiov Media Med 2001;24(3):129-31.

11 Axelsson B, Boden K, Fransson SG, et al. A comparison of analogue and digital techniques in upper gastrointestinal examinations: absorbed dose and diagnostic quality of the images. Eur Radiol 2000;10(8):1351-4.

\section{1th European Forum on Quality Improvement in Health Care}

26-28 April 2006, Prague, Czech Republic

For further information please go to: www.quality.bmjpg.com Book early to benefit from a discounted delegate rate 